\title{
Is radioiodine administration in patients with papillary thyroid multifocal microcarcinoma unnecessary?
}

\author{
Eva Krčálová1,5, Jiří Horáček2,5, Lubomír Kudlej3, Viera Rousková4, Blanka Michlová1, \\ Irena Vyhnánková1, Jiří Doležal', Jaroslav Malý2,5 and Pavel Žák2,5 \\ ${ }^{1}$ Nuclear Medicine Department, University Hospital Hradec Kralove, Hradec Kralove, Czech Republic, \\ 24th Department of Internal Medicine, Charles University in Prague, Faculty of Medicine and University \\ Hospital Hradec Kralove, Hradec Kralove, Czech Republic, IInternal Medicine Department, \\ ${ }^{4}$ Nuclear Medicine Department, Hospital Trutnov, Trutnov, Czech Republic, and ${ }^{5}$ Academic Department \\ of Internal Medicine, Charles University in Prague, Faculty of Medicine in Hradec Kralove, Hradec \\ Kralove, Czech Republic
}

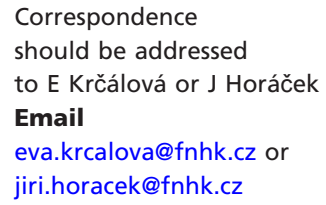

\section{Summary}

Radioiodine (RAI) has played a crucial role in differentiated thyroid cancer treatment for more than 60 years. However, the use of RAI administration in patients with papillary thyroid microcarcinoma (even multifocal) is now being widely discussed and often not recommended. In accordance with European consensus, and contrary to the American Thyroid Association (ATA) guidelines, we recently performed RAI thyroid remnant ablation in a patient with differentiated papillary multifocal microcarcinoma. The post-therapeutic whole-body scan and SPECT/CT revealed the real and unexpected extent of disease, with metastases to upper mediastinal lymph nodes. This finding led to the patient's upstaging from stage I to stage IVa according to the American Joint Committee on Cancer/International Union Against Cancer criteria.

\section{Learning points:}

- 1311 is a combined beta-gamma emitter, thus allowing not only residual thyroid tissue ablation but also metastatic tissue imaging.

- RAI remnant ablation omission also means post-treatment whole-body scan omission, which may lead to disease underestimation, due to incorrect nodal and metastatic staging.

- RAl should be considered also in "low-risk" patients, especially when the lymph node involvement is not reliably documented.

- Lower administered RAl activity $(30 \mathrm{mCi}, 1.1 \mathrm{GBq})$ may be a workable compromise in low-risk patients, not indicated for RAl remnant ablation according to ATA guidelines.

\section{Background}

Differentiated thyroid cancer (DTC) therapy has long consisted of total thyroidectomy, occasionally accompanied by neck lymph node dissection, radioiodine (RAI) administration and levothyroxine suppression therapy.
Due to a sharp increase in the incidence of DTC, with prevailing small (below $2 \mathrm{~cm}$ ), low-risk tumours (1), the necessity of RAI remnant ablation in these low-risk patients has recently been discussed $(2,3)$. 


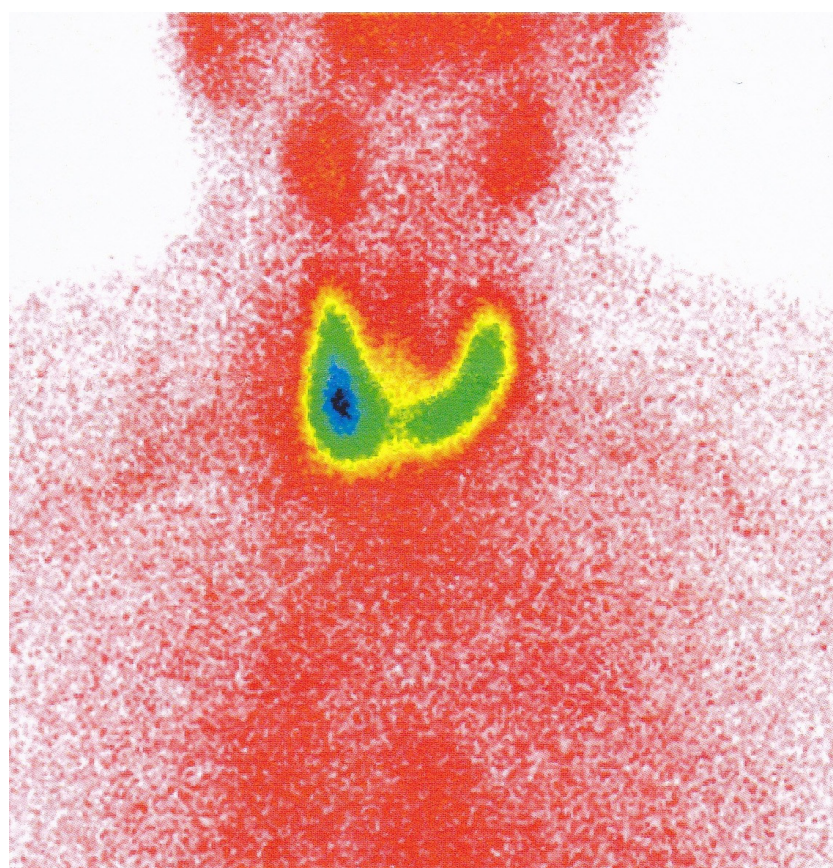

Figure 1

Thyroid scan with 99mTc-pertechnetate (with permission from V. Rouskova, $M D$ ).

American Thyroid Association (ATA) guidelines do not recommend RAI remnant ablation in patients with well-differentiated microcarcinoma, even multifocal, in the absence of worrisome histological features (4).

According to European consensus, RAI administration is probably indicated even in patients with microcarcinoma if no neck lymph node dissection was performed (5).

While retrospective studies suggest that RAI omission does not influence long-term outcome in low-risk patients $(4,5,6)$, there are no reliable data from long-term prospective randomised controlled studies, which leaves this question open (7).

In addition, RAI treatment also provides an important diagnostic tool in accurate TNM disease staging, as demonstrated in our case report.

\section{Case presentation}

In a 62-year-old man, laboratory tests on routine screening revealed hyperthyroidism: thyrotrophin (TSH) $0.065 \mathrm{mIU} / \mathrm{L}$, free thyroxine (fT4) $16.67 \mathrm{pmol} / \mathrm{L}$, and free triiodothyronine (fT3) $9.61 \mathrm{pmol} / \mathrm{L}$. Methimazole $(30 \mathrm{mg} /$ day) was administered and the patient was referred to an endocrinologist.

\section{Investigation}

The endocrinologist checked the laboratory tests: TSH, fT4, and fT3 were then normalised due to the methimazole treatment. Thyroid gland ultrasonography disclosed a hypoechoic inhomogeneous nodule $(20 \mathrm{~mm})$ with calcifications in the lower part of the right lobe. In addition, several small cysts (up to $5 \mathrm{~mm}$ ) in the upper part of the right lobe were described. The appearance of the left lobe was unremarkable and lymphadenopathy was not present. Static thyroid gland scintigraphy with $99 \mathrm{~m}$ Tc-pertechnetate confirmed a small warm nodule in the lower part of right thyroid lobe, corresponding to the nodule on ultrasonography (Fig. 1).

Right thyroid lobe resection was performed, and histology revealed not only the hyperplastic nodule but also 3 foci of papillary microcarcinoma - all within $6 \mathrm{~mm}$. One of them was a follicular variant of papillocarcinoma. The presence of locoregional or vascular invasion was not detected. Completion thyroidectomy was performed within 10 days. In the left lobe, no cancer was found. As no enlarged lymph nodes were detected preoperatively, no lymph node dissection was performed.

\section{Treatment}

After 6 weeks of thyroid hormone withdrawal, the patient was admitted to our thyroid unit for RAI remnant ablation. He was hypothyroid as required (TSH level above $50 \mathrm{mIU} / \mathrm{L}$, undetectable fT4, and low fT3). Ultrasonography showed only small remnants in the thyroid bed and no suspicious neck lymph nodes. RAI uptake after $24 \mathrm{~h}$ was only $2.3 \%$, thus meeting the RAI remnant ablation requirements. Serum thyroglobulin (Tg) level was $11.03 \mu \mathrm{g} / \mathrm{mL}$. The patient underwent RAI remnant ablation with $100 \mathrm{mCi}$ $(3.7 \mathrm{GBq}){ }^{131} \mathrm{I}$.

\section{Outcome and follow-up}

The post-ablation scan revealed not only remnants in the thyroid bed, but surprisingly also metastatic lymphatic tissue in the upper mediastinum (two lymph nodes in front of the trachea and one in front of the upper vena cava - as clearly visible on the SPECT/CT) (Figs 2 and 3)

This changed his TNM classification from $\mathrm{T} 1 \mathrm{a}(\mathrm{m})$ NOM0 to T1a $(\mathrm{m}) \mathrm{N} 1 \mathrm{bM} 0$, and the staging from stage I to stage IVa, according to American Joint Committee on Cancer/International Union Against Cancer (AJCC/UICC) criteria. 


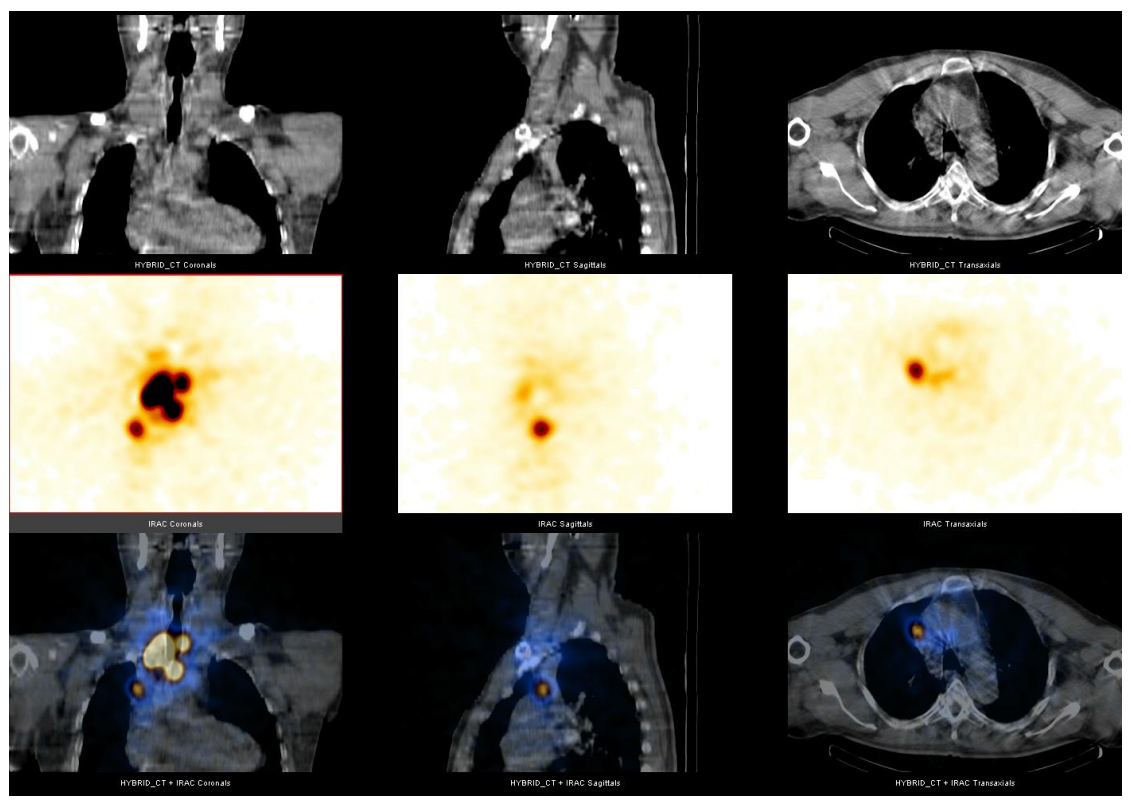

Figure 2

131| post-ablation hybrid SPECT/low dose CT images demonstrating neck and mediastinal metastases (top row: $\mathrm{CT}$ images, middle row: SPECT images with attenuation correction, lower row: fused SPECT/low dose CT images).

\section{Discussion}

ATA does not recommend RAI ablation for patients with microcarcinomas or multifocal cancer when the foci are smaller than $1 \mathrm{~cm}$ (4). This approach seems to be supported by several studies. For example, Schvartz et al. in their retrospective cohort study with 1298 patients (and a follow-up period of 10 years) did not show any survival benefit of RAI ablation in low-risk patients (defined according to ATA guidelines) (6).

Nevertheless, who are the low-risk patients?

Our case report highlights the sticking point of thyroid cancer management, i.e. reliable lymph node evaluation. Moreover, this is the crucial point because, in the presence of lymph node metastases, the patient is certainly not low-risk according to any recommendation $(4,5)$. Still, at the time of decision for or against RAI remnant ablation, the 'negative' information on metastatic lymph nodes may not be very reliable.

ATA guidelines do not recommend lymph node dissection in $\mathrm{T} 1$ and $\mathrm{T} 2$ tumours. European consensus advises neck lymph node dissection only if there is a suspicion. Therefore, for most patients, we do not have any direct data from surgery and histology. According to European consensus, such patients would be in the 'probable indication' group for RAI administration (5), as it was in our patient.

Ultrasonography may be a workable alternative, but it is highly operator-dependent, and often not sufficiently sensitive. Using post-ablation SPECT/CT in 85 patients with microcarcinoma and no suspected nodal involvement at ultrasonography, Gallicchio et al. found 30 (i.e. 35\%) metastatic neck lymph nodes (8). Furthermore, mediastinal lymph nodes are sonographically unattainable at all (unless very proximal). Our case report demonstrates this problem clearly.

Therefore, the real extent of the disease after surgery may not be well documented. As also small 'low-risk' tumours below $10 \mathrm{~mm}$ may produce nodal or distant metastases, some authors still advocate RAI remnant ablation in all DTC patients $(2,7)$, in contrast to the official recommendations $(4,5)$. In fact, while heterogeneous population of low-risk DTC patients is rapidly growing,

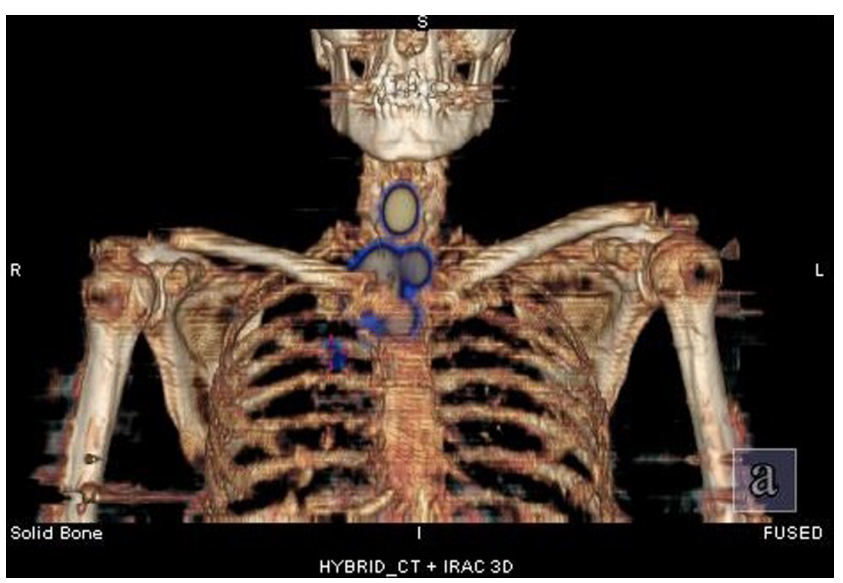

Figure 3

Volume-rendering technique reconstruction, where metastatic upper mediastinal nodes are clearly visible. (Gammacamera: Infinia Hawkeye 4, GE, Milwaukee, USA; combined with four slice helical CT system). 
we have not had any data from sufficiently long-term prospective randomised studies comparing the relapse rate and survival in low-risk DTC patients supporting either liberal or strict approach towards radioiodine remnant ablation.

Certainly, survival in DTC is greatly affected by careful lifelong follow-up, as many patients with relapsing disease can be successfully treated with RAI. Another argument for a more liberal approach towards RAI treatment in low-risk patients may be that post-surgical RAI remnant ablation makes this follow-up (using thyroglobulin levels and RAI scintigraphy) more efficient.

From carefully designed randomised controlled studies by Schlumberger et al. (9) and Malick et al. (10), we know that remnant ablation may be successfully performed using a lower activity $(30 \mathrm{mCi}, 1.1 \mathrm{GBq})$, with lower radiation exposure. While we do not know how the lower activity will affect the long-term relapse rate and survival, it may also be useful in lymph node involvement detection, thus making the staging more precise.

Using lower activity may thus be a workable theranostic alternative in 'low-risk' DTC patients with unreliable information on the lymph node involvement.

\section{Declaration of interest}

The authors declare that there is no conflict of interest that could be perceived as prejudicing the impartiality of the research reported.

\section{Funding}

This work was supported by grant SVV-2016-260286.

\section{Patient consent}

The patient's informed consent for the article and accompanying image publication was obtained. A signed copy of informed consent is enclosed.

\section{Author contribution statement}

E Krcalova wrote the manuscript and prepared the volume-rendering technique reconstructions. B Michlova is the patient's physician; B Michlová gave E Krčálová permission to write the manuscript. L Kudlej is the endocrinologist. V Rousková, B Michlová, and I Vyhnánková performed the nuclear medicine imaging studies. J Horáček, J Doležal, J Malý, and P Žák gave important clinical advice, reviewed the manuscript, and contributed to the discussion.

\section{References}

1 Davies L \& Welch HG 2006 Increasing incidence of thyroid cancer in the United States. 1973-2002. JAMA 295 2164-2167. (doi:10.1001/ jama.295.18.2164)

2 Ain KB 2015 Radioiodine-remnant ablation in low-risk differentiated thyroid cancer: pros. Endocrine 50 61-66. (doi:10.1007/s12020-0150668-9)

3 Lamartina L \& Cooper DS 2015 Radioiodine-remnant ablation in lowrisk differentiated thyroid cancer: the "con" point of view. Endocrine 50 67-71. (doi:10.1007/s12020-014-0523-4)

4 Cooper DS, Doherty GM, Haugen BR, Kloos RT, Lee SL, Mandel SJ, Mazzaferri EL, McIver B, Pacini F, Schlumberger M, et al. 2009 Revised American Thyroid Association management guidelines for patients with thyroid nodules and differentiated thyroid cancer. Thyroid $\mathbf{1 1}$ 1167-1199. (doi:10.1089/thy.2009.0110)

5 Pacini F, Schlumberger M, Dralle H, Elisei R, Smit JWA, Wiersinga W \& European Thyroid Cancer Taskforce 2006 European consensus for the management of patients with differentiated thyroid carcinoma of the follicular epithelium. European Journal of Endocrinology $\mathbf{1 5 4}$ 787-803. (doi:10.1530/eje.1.02158)

6 Schvartz C, Bonnetain F, Dabakuyo S, Gauthier M, Cueff A, Feiffé S, Pochart JM, Cochet I, Crevisy E, Dalac A, et al. 2012 Impact on overall survival of radioactive iodine in low - risk differentiated thyroid cancer patients. Journal of Clinical Endocrinology and Metabolism 5 1526-1535. (doi:10.1210/jc.2011-2512)

7 Blumhardt R, Wolin EA, Phillips WT, Salman UA, Walker RC, Stack BC Jr \& Metter D 2014 Current controversies in the initial post-surgical radioactive iodine therapy for thyroid cancer: a narrative review. Endocrine-Related Cancer 21 R473-R484. (doi:10.1530/ERC-14-0286)

8 Gallicchio R, Giacomobono S, Capacchione D, Nardelli A, Barbato F, Nappi A, Pellegrino T \& Storto G 2013 Should patients with remnants from thyroid microcarcinoma really not be treated with iodine-131 ablation? Endocrine 44 426-433. (doi:10.1007/s12020-013-9935-9)

9 Schlumberger M, Catargi B, Borget I, Deandreis D, Zerdoud S, Bridji B, Bardet S, Leenhardt L, Bastie D, Schvartz C, et al. 2012 Strategies of radioiodine ablation in patients with low - risk thyroid cancer. New England Journal of Medicine 366 1663-1673. (doi:10.1056/ NEJMoa1108586)

10 Mallick U, Harmer C, Yap B, Wadsley J, Clarke S, Moss L, Nicol A, Clark PM, Farnell K, McCready R, et al. 2012 Ablation with low-dose radioiodine and thyrotropin alfa in thyroid cancer. New England Journal of Medicine 366 1674-1685. (doi:10.1056/NEJMoa1109589)

Received in final form 16 March 2016

Accepted 12 April 2016 